\title{
Leptin Deficiency, Caused by Malnutrition, Makes You Susceptible to SARS-CoV-2 Infection but Could Offer Protection from Severe COVID-19
}

\author{
Dewald Schoeman, ${ }^{a}$ (D) Burtram C. Fielding ${ }^{a}$ \\ aMolecular Biology and Virology Research Laboratory, Department of Medical Biosciences, University of the Western Cape, Bellville, Cape Town, Western Cape, South \\ Africa
}

ABSTRACT In much of the developing world, severe malnutrition is the most prevalent cause of immunodeficiency and affects up to $50 \%$ of the population in some impoverished communities. As yet, we do not know how severe acute respiratory syndrome coronavirus 2 (SARS-CoV-2) will behave in populations with immunodeficiency caused by malnourishment. Interestingly, researchers are now speculating that, in some instances, a defective cellular immune system could paradoxically be a protective factor against severe disease in certain patients contracting SARS-CoV and SARS-CoV-2. This could be linked to the absence of T-cell activation. Based on available information presented here, it is plausible that the hyperimmune response, and subsequent cytokine storm often associated with severe coronavirus disease 2019 (COVID-19), could be "counteracted" by the defective immune response seen in individuals with malnutrition-induced leptin deficiency. In this paper, we proposed a theory that although those with malnutrition-linked leptin deficiency are at risk of SARS-CoV-2 infection, they are at lower risk of developing severe COVID-19.

KEYWORDS COVID-19, SARS-CoV-2, undernutrition, leptin deficiency, cytokine storm, malnutrition
Citation Schoeman D, Fielding BC. 2021. Leptin deficiency, caused by malnutrition makes you susceptible to SARS-CoV-2 infection but could offer protection from severe COVID19. mSphere 6:e00031-21. https://doi.org/10 $.1128 / \mathrm{mSphere} .00031-21$

Editor Marcela F. Pasetti, University of Maryland School of Medicine

Copyright $\odot 2021$ Schoeman and Fielding. This is an open-access article distributed under the terms of the Creative Commons Attribution 4.0 International license. Address correspondence to Burtram C. Fielding, bfielding@uwc.ac.za.

Published 12 May 2021 passes all the various therapies, pathogens, cancers, autoimmune conditions, and 
monogenic disorders that can trigger such an event. Nevertheless, it can generally be regarded as an excessive immune response, one that may be greater than its immediate benefit, that causes collateral damage to organs, and is accompanied by elevated levels of circulating cytokines (6). Although the exact cause of the cytokine storm in severe COVID-19 is not yet clear, it stands to reason that the SARS-CoV-2 virus plays a central role, since similar features have been observed in SARS-CoV, MERS-CoV, as well as other viral infections (7). This paper will focus on the immunosuppressive effect of leptin deficiency-linked malnutrition in the context of SARS-CoV-2, and the concomitant hyperinflammatory response seen in severe COVID-19 (6).

Viral infections can trigger secondary/acquired hemophagocytic lymphohistiocytosis (sHLH) - a hyperinflammatory syndrome-mainly resulting in an unremitting fever, cytopenias, and pulmonary involvement (including ARDS) in about half of patients (8). Left untreated, sHLH leads to a cytokine storm and hemophagocytosis, resulting in fatal hypercytokinemia with multiorgan failure (9). In severe lung infections, the cytokine storm-linked inflammatory response can move into the systemic circulation, producing systemic sepsis, which could result in the damage of other organs (10). Interestingly, severe COVID-19 is associated with a cytokine profile similar to that of sHLH (11), and increasing evidence shows elevated levels of inflammatory cells, cytokines, chemokines, and other inflammatory mediators associated with severe COVID19 (1, 12-14). Since COVID-19 also closely resembles SARS, and ARDS progression in severe SARS is marked by a similar elevation in inflammatory cytokines, it is reasonable to conclude that similar immunopathogenic features are to be expected in severe COVID-19 cases (15). Although ARDS and the accompanying respiratory failure are the leading causes of death in severe COVID-19 cases, the hyperinflammatory response from the cytokine storm facilitates the immunopathology that culminates in ARDS and respiratory failure (16). In fact, inflammation from the hyperactivated immune response increases capillary permeability and damages the alveolar-capillary membrane, bringing about pulmonary edema, impairing gas exchange, and often culminating in respiratory failure, characteristic features of $\operatorname{ARDS}(1,17)$.

Malnutrition, and protein energy malnutrition (PEM) in particular, has been linked to an immunosuppressive phenotype. This phenotype is characterized by reduced proinflammatory cytokines, notably interleukin 2 (IL-2), IL-6, IL-12, gamma interferon (IFN- $\gamma$ ), tumor necrosis factor alpha (TNF- $\alpha$ ); an impaired response from inflammatory T-cells $\left(\mathrm{CD} 69^{+}, \mathrm{CD} 25^{+}\right)$, dendritic cells (DCs) $\left(\mathrm{HLA}^{-D R^{+}}\right)$, and macrophages $\left(\mathrm{CD} 14^{+}\right)$upon stimulation; and a concomitant increase in anti-inflammatory cytokines, such as IL-4, IL-10, and transforming growth factor beta (TGF- $\beta$ ) (18-20). These studies demonstrate that PEM brings about an immunological shift in the balance of cytokines, favoring an anti-inflammatory response, and this is in stark contrast to what has been reported for a cytokine storm; a hyperinflammatory event in which proinflammatory cytokine levels are increased and those of anti-inflammatory cytokines are decreased (Fig. 1). Clearly, the cytokine profile of persons suffering from PEM is inverse to that of a cytokine storm, as many of the damaging, proinflammatory cytokines from the storm are inversely regulated to antiinflammatory cytokines. This immunosuppressive phenotype, however, gives rise to a phenomenon called "immunoparalysis" - a persistently high anti-inflammatory immune response following infection. Since a proper immunological balance between pro- and anti-inflammatory processes is vital for recovery from critical illness, it has been proposed that patients who survive the cytokine storm, but subsequently die, may be those who did not recover from immunoparalysis (21). Accordingly, malnutrition does not necessarily protect against COVID-19 itself but rather appears to counteract the severe complications brought on by the cytokine storm as a consequence of the infection.

Malnourished individuals commonly have decreased levels of the adipokine, viz. leptin, and this deficiency in leptin has been linked to the impaired immune function typically seen in malnourished persons (22-24). Leptin has been shown to shift the immune response from an anti-inflammatory profile to a more proinflammatory one, validating the observed immunosuppressive phenotype seen in such leptin-deficient 


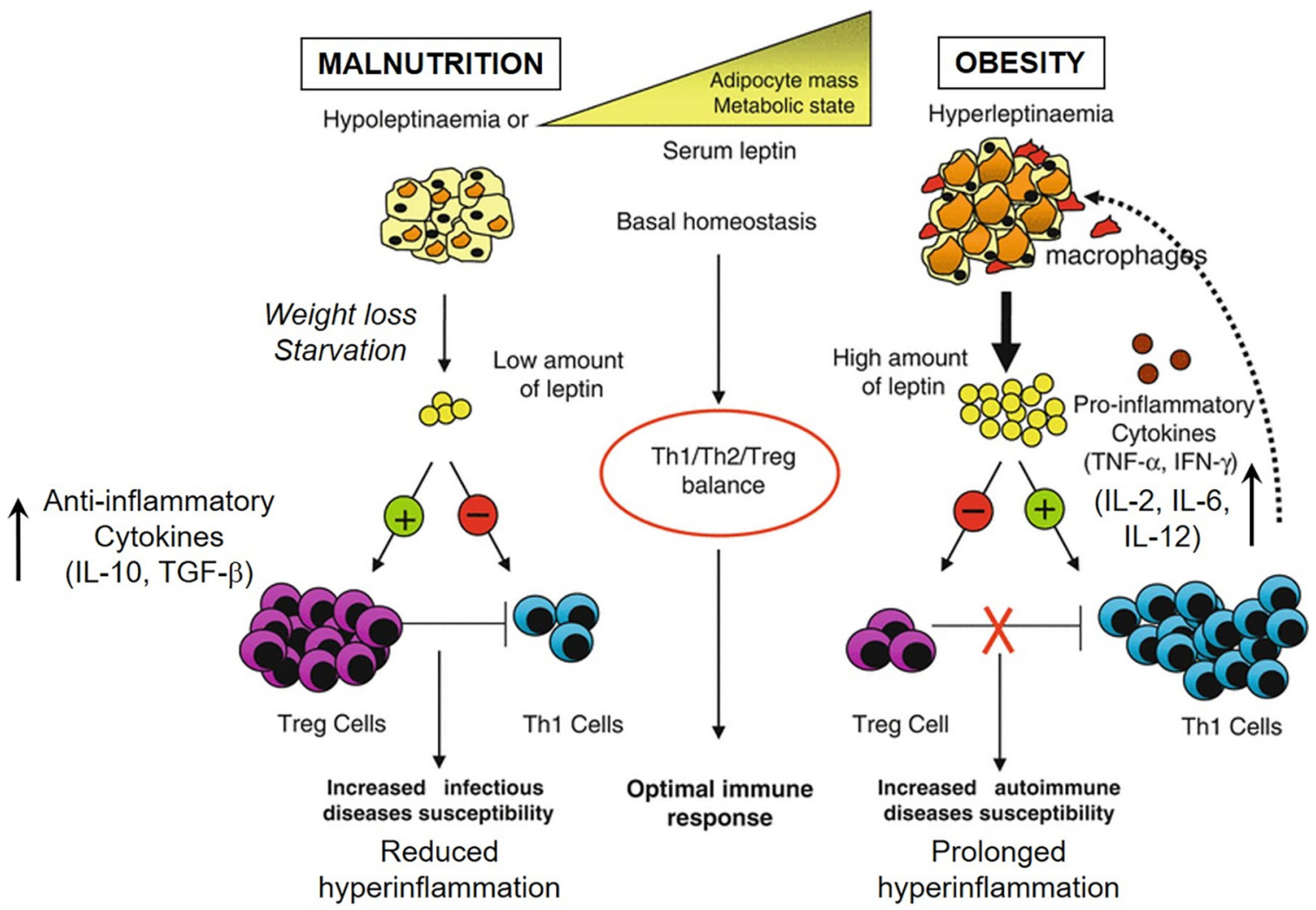

FIG 1 Leptin modulates the immune response by acting on both effector $T$ (Teff) cells and regulatory $T$ (Treg) cells. Under homeostatic conditions, adipocytes secrete basal levels of leptin that positively regulate Th1 immunity through the proliferation of Teff cells and, simultaneously, regulate Treg cell expansion negatively. This achieves an optimal immune profile-a balance between Teff and Treg cells, whereby Tregs mediate immune tolerance through anti-inflammatory cytokine production, while Th1 cells confer protection from infections through proinflammatory cytokine production. Reduced leptin levels (hypoleptinaemia), as a consequence of weight loss or malnutrition (starvation), reduce Teff cell proliferation and increase Treg cell expansion. This downregulates Th1 immunity and produces an immune response skewed toward an anti-inflammatory profile, increasing a person's susceptibility to infections by reducing the Th1-mediated inflammatory response. Accordingly, malnourished persons are predisposed to contracting infections but can be protected from hyperinflammatory conditions by this anti-inflammatory profile. Conversely, high leptin secretion (hyperleptinaemia), attributed to increased adipocyte mass as seen in obesity, triggers Teff expansion and reduces Treg cell proliferation. This skews the immune response toward a proinflammatory profile, increasing the person's risk to hyperinflammatory conditions by reducing the Treg-mediated anti-inflammatory response. Accordingly, such persons are predisposed to hyperinflammatory conditions and can experience more severe inflammatory responses on account of the proinflammatory immune profile. Adapted from reference 40 .

malnourished persons $(25,26)$. This effect has been demonstrated in animal models and other infectious diseases, where subsequent administration of leptin also reversed the effects of leptin deficiency observed on immunosuppression $(6,27)$. This specifically demonstrated that severe protein-restricted (malnourished) BALB/c mice, infected with visceral leishmaniasis, expressed significantly higher levels of anti-inflammatory cytokines (IL-4, IL-10, and TGF- $\beta$ ) compared to infected mice on a regular protein diet. Subsequent administration of leptin to these malnourished, infected mice significantly decreased the expression of IL-4, IL-10, and TGF- $\beta$, directly implicating leptin in shifting the immune response from an anti-inflammatory profile to a proinflammatory one. Human clinical studies on malnutrition-linked immunodeficiency would, therefore, benefit greatly from measuring the leptin levels of malnourished persons and comparing it to that of well-nourished persons to determine whether such a significant difference could support the observed differences in their immunological profile. One study measured the serum leptin levels in both SARS-CoV-2-infected and uninfected patients and reported a positive correlation between the serum leptin levels and body mass index (BMI) of infected persons (28). Although the authors did not include immunological markers, they described a clinical and biological framework in which they proposed that the increased BMI and accompanying serum leptin levels could explain the need for 
SARS-CoV-2-infected patients to receive mechanical ventilation, implicating the increased $\mathrm{BMI}$ and serum leptin levels in acute pulmonary inflammation.

Several studies have used BMI as the only marker for obesity. However, we caution against this. The use of BMI alone as a marker for obesity is an accepted Western norm, which we recommend should be accompanied by additional adiposity markers such as waist circumference, waist-to-hip/height ratio, and/or body fat percentage to classify persons more accurately as overweight or obese. Accordingly, S. A. Peters et al. (29) reported that higher adiposity markers, viz. BMI, waist circumference, waist-to-hip ratio, and waistto-height ratio, are associated with a greater risk of mortality from COVID-19. T. Yates et al. (30) also reported a dose-response association between BMI and waist circumference and testing positive for COVID-19, and C. Razieh et al. (31) similarly reported a difference in the risk of COVID-19 between ethnic groups based on BMI and waist circumference. Furthermore, J. Wang et al. (32) used both BMI and serum leptin levels, reporting that patients with a high BMI have significantly higher levels of leptin. This is also positively associated with inflammatory mediators and disease severity in such patients.

Admittedly, we cannot generalize, and our hypothesis might not be applicable to all developing countries due to innate differences in diet and nutritional states, among other factors. Also, our hypothesis might not be relevant to all elderly persons in developing countries since "immunosenescence" and "inflammaging" could also contribute to COVID-19 age-related mortality. A marked decrease in both CD4+ helper T cellsthat help to clear viral infections-and immunosuppressive T cells (Tregs) ("immunosenescence"), accompanied by a chronic, low-grade inflammatory state from increased serum inflammatory mediators ("inflammaging") would be additional factors relevant for consideration in this elderly population (33).

Implications of leptin deficiency-induced immunosuppression for biomarkers and vaccine development. Worryingly, the data from these studies suggest that malnutrition could also cause a deficient vaccine response. The importance of both DCs and IL-2 in the development of a functional immunological memory strongly suggests that a reduced vaccine response could likely be the result of impaired DC function, insufficient IL-2 levels to prime effector memory $T$ cells, and an impaired response from effector memory $T$ cells that have formed $(34,35)$. This could also have dire implications for vaccine administration as immunodeficiency-linked malnutrition might not simply be "corrected" by vaccination. These studies clearly implicate a metabolic requirement in the mounting and maintenance of functional immunological memory, which is paramount to an effective vaccine response $(25,26)$.

A neglected aspect of the leptin-immune axis that could also have implications for vaccine development, is the effect of leptin on antibody production. Leptin downregulates antibody production and class switching, and since serum leptin levels are elevated in both obese and elderly persons, this should be considered to ensure the development of effective vaccines for these vulnerable groups (36). Interestingly, this study also found that rapamycin rescues the negative leptin-induced effect on B cells. Furthermore, the impact of leptin on the immune system and its correlation with disease progression and severity would make it a valuable predictive tool, or biomarker, for predicting patient prognosis (32). Naturally, its efficacy as a biomarker would first have to be tested and confirmed, but it could prove especially useful in Africa and other developing countries, where treatments are often sparse and expensive and not everyone has access to primary health care. Leptin's use as a biomarker could also assist in developing a risk-based approach where a patient's leptin levels could be used to evaluate whether the patient could benefit from early, prophylactic treatment, such as dexamethasone or any other relevant COVID-approved treatment(s).

In this paper, we proposed that individuals with leptin deficiency-linked immunosuppression due to malnutrition are not at higher risk of developing severe COVID-19 compared to healthy, well-nourished individuals with physiologically "normal" leptin levels. Malnourished persons can still contract COVID-19, but they are less likely to die from the hyperinflammation brought on by the cytokine storm. Interestingly, researchers have now speculated that a defective cellular immune system-as seen in HIV 
patients- "could paradoxically be a protective factor in some patients" contracting SARS-CoV (37). Similarly, for SARS-CoV-2, "the compromised immunity might be the reason that HIV/AIDS patients did not occur inflammatory changes and clinical symptoms" associated with severe COVID-19 (38), which could be linked to the absence of T-cell activation (39). Based on available information, it is plausible that the hyperimmune response, and subsequent cytokine storm often associated with severe COVID19 , could be "counteracted" by the defective immune response seen in individuals with malnutrition-induced leptin deficiency.

\section{ACKNOWLEDGMENTS}

Burtram C. Fielding receives funding from the National Research Foundation (NRF) (South Africa). Dewald Schoeman receives funding from the Poliomyelitis Research Foundation (PRF) under grant number 17/53. Any opinion, findings and conclusions or recommendations expressed in this material are those of the authors, and therefore, the NRF does not accept any liability in regard thereto. Open access publication fees were paid by the University of the Western Cape Senate Research Committee Page Fee Fund.

Any opinion, findings and conclusions or recommendations expressed in this material are those of the authors, and therefore, the NRF does not accept any liability in regard thereto.

We apologize to any author whose work has been inadvertently omitted from this paper.

We declare that the research was conducted in the absence of any commercial or financial relationships that could be construed as a potential conflict of interest.

Both authors drafted, read, edited, and approved the final manuscript.

\section{REFERENCES}

1. Channappanavar R, Perlman S. 2017. Pathogenic human coronavirus infections: causes and consequences of cytokine storm and immunopathology. Semin Immunopathol 39:529-539. https://doi.org/10.1007/ s00281-017-0629-x

2. Sohrabi C, Alsafi Z, O'Neill N, Khan M, Kerwan A, Al-Jabir A, losifidis C, Agha R. 2020. World Health Organization declares global emergency: a review of the 2019 novel coronavirus (COVID-19). Int J Surg 76:71-76. https://doi.org/ 10.1016/j.jjsu.2020.02.034.

3. WHO. 2020. Weekly epidemiological update - 1 December 2020. World Health Organization, Geneva, Switzerland. https://www.who.int/publications/m/item/ weekly-epidemiological-update---1-december-2020. Accessed 7 December 2020.

4. Cron RQ. 2021. COVID-19 cytokine storm: targeting the appropriate cytokine. Lancet Rheumatol 3:e236-e237. https://doi.org/10.1016/ S2665-9913(21)00011-4.

5. Mehta P, McAuley DF, Brown M, Sanchez E, Tattersall RS, Manson JJ, HLH Across Speciality Collaboration, UK. 2020. COVID-19: consider cytokine storm syndromes and immunosuppression. Lancet 395:1033-1034. https:// doi.org/10.1016/S0140-6736(20)30628-0.

6. Fajgenbaum DC, June CH. 2020. Cytokine storm. N Engl J Med 383:2255-2273. https://doi.org/10.1056/NEJMra2026131.

7. Zhang YY, Li BR, Ning BT. 2020. The comparative immunological characteristics of SARS-CoV, MERS-CoV, and SARS-CoV-2 coronavirus infections. Front Immunol 11:2033. https://doi.org/10.3389/fimmu.2020.02033.

8. Seguin A, Galicier L, Boutboul D, Lemiale V, Azoulay E. 2016. Pulmonary involvement in patients with hemophagocytic lymphohistiocytosis. Chest 149:1294-1301. https://doi.org/10.1016/j.chest.2015.11.004.

9. Ramos-Casals M, Brito-Zeron P, Lopez-Guillermo A, Khamashta MA, Bosch X. 2014. Adult haemophagocytic syndrome. Lancet 383:1503-1516. https://doi.org/10.1016/S0140-6736(13)61048-X.

10. Tisoncik JR, Korth MJ, Simmons CP, Farrar J, Martin TR, Katze MG. 2012. Into the eye of the cytokine storm. Microbiol Mol Biol Rev 76:16-32. https://doi.org/10.1128/MMBR.05015-11.

11. Huang C, Wang $Y$, Li X, Ren L, Zhao J, Hu Y, Zhang L, Fan G, Xu J, Gu X, Cheng Z, Yu T, Xia J, Wei Y, Wu W, Xie X, Yin W, Li H, Liu M, Xiao Y, Gao H, Guo L, Xie J, Wang G, Jiang R, Gao Z, Jin Q, Wang J, Cao B. 2020. Clinical features of patients infected with 2019 novel coronavirus in Wuhan, China. Lancet 395:497-506. https://doi.org/10.1016/S0140-6736(20)30183-5.

12. Chen G, Wu D, Guo W, Cao Y, Huang D, Wang H, Wang T, Zhang X, Chen H, Yu H, Zhang X, Zhang M, Wu S, Song J, Chen T, Han M, Li S, Luo X, Zhao J, Ning Q. 2020. Clinical and immunological features of severe and moderate coronavirus disease 2019. J Clin Invest 130:2620-2629. https://doi .org/10.1172/JCl137244.

13. Chen L, Liu HG, Liu W, Liu J, Liu K, Shang J, Deng Y, Wei S. 2020. Analysis of clinical features of 29 patients with 2019 novel coronavirus pneumonia. Zhonghua Jie He He Hu Xi Za Zhi 43:203-208.

14. Liao M, Liu Y, Yuan J, Wen Y, Xu G, Zhao J, Cheng L, Li J, Wang X, Wang F, Liu L, Amit I, Zhang S, Zhang Z. 2020. Single-cell landscape of bronchoalveolar immune cells in patients with COVID-19. Nat Med 26:842-844. https://doi.org/10.1038/s41591-020-0901-9.

15. Ye Q, Wang B, Mao J. 2020. The pathogenesis and treatment of the 'cytokine storm' in COVID-19. J Infect 80:607-613. https://doi.org/10.1016/j.jinf .2020.03.037.

16. De Wit E, Van Doremalen N, Falzarano D, Munster VJ. 2016. SARS and MERS: recent insights into emerging coronaviruses. Nat Rev Microbiol 14:523-534. https://doi.org/10.1038/nrmicro.2016.81.

17. Jimenez-Guardeño JM, Nieto-Torres JL, DeDiego ML, Regla-Nava JA, Fernandez-Delgado R, Castaño-Rodriguez C, Enjuanes L. 2014. The PDZbinding motif of severe acute respiratory syndrome coronavirus envelope protein is a determinant of viral pathogenesis. PLoS Pathog 10:e1004320. https://doi.org/10.1371/journal.ppat.1004320.

18. Rodriguez L, Gonzalez C, Flores L, Jimenez-Zamudio L, Graniel J, Ortiz R. 2005. Assessment by flow cytometry of cytokine production in malnourished children. Clin Diagn Lab Immunol 12:502-507. https://doi.org/10 .1128/CDLI.12.4.502-507.2005.

19. Gonzalez-Torres C, Gonzalez-Martinez H, Miliar A, Najera O, Graniel J, Firo V, Alvarez C, Bonilla E, Rodriguez L. 2013. Effect of malnutrition on the expression of cytokines involved in Th1 cell differentiation. Nutrients 5:579-593. https://doi.org/10.3390/nu5020579.

20. Dai G, McMurray DN. 1998. Altered cytokine production and impaired antimycobacterial immunity in protein-malnourished guinea pigs. Infect Immun 66:3562-3568. https://doi.org/10.1128/IAI.66.8.3562-3568.1998. 
21. Frazier WJ, Hall MW. 2008. Immunoparalysis and adverse outcomes from critical illness. Pediatr Clin North Am 55:647-668, xi. https://doi.org/10 .1016/j.pcl.2008.02.009.

22. Naylor C, Petri WA, Jr. 2016. Leptin regulation of immune responses. Trends Mol Med 22:88-98. https://doi.org/10.1016/j.molmed.2015.12.001.

23. Lord GM, Matarese G, Howard JK, Baker RJ, Bloom SR, Lechler RI. 1998. Leptin modulates the $\mathrm{T}$-cell immune response and reverses starvationinduced immunosuppression. Nature 394:897-901. https://doi.org/10 $.1038 / 29795$.

24. Cohen S, Danzaki K, Maclver NJ. 2017. Nutritional effects on T-cell immunometabolism. Eur J Immunol 47:225-235. https://doi.org/10 .1002/eji.201646423.

25. Rodriguez L, Graniel J, Ortiz R. 2007. Effect of leptin on activation and cytokine synthesis in peripheral blood lymphocytes of malnourished infected children. Clin Exp Immunol 148:478-485. https://doi.org/10 $.1111 / j .1365-2249.2007 .03361 . x$.

26. Palacio A, Lopez M, Perez-Bravo F, Monkeberg F, Schlesinger L. 2002. Leptin levels are associated with immune response in malnourished infants. J Clin Endocrinol Metab 87:3040-3046. https://doi.org/10.1210/ jcem.87.7.8636.

27. Dayakar A, Chandrasekaran S, Veronica J, Bharadwaja V, Maurya R. 2017. Leptin regulates Granzyme-A, PD-1 and CTLA-4 expression in T cell to control visceral leishmaniasis in BALB. Sci Rep 7:14664. https://doi.org/10 .1038/s41598-017-15288-7.

28. van der Voort PHJ, Moser J, Zandstra DF, Muller Kobold AC, Knoester M, Calkhoven CF, Hamming I, van Meurs M. 2020. Leptin levels in SARS-CoV2 infection related respiratory failure: a cross-sectional study and a pathophysiological framework on the role of fat tissue. Heliyon 6:e04696. https://doi.org/10.1016/j.heliyon.2020.e04696.

29. Peters SA, MacMahon S, Woodward M. 2021. Obesity as a risk factor for COVID-19 mortality in women and men in the UK Biobank: comparisons with influenza/pneumonia and coronary heart disease. Diabetes Obes Metab 23:258-262. https://doi.org/10.1111/dom.14199.

30. Yates T, Razieh C, Zaccardi F, Davies MJ, Khunti K. 2020. Obesity and risk of COVID-19: analysis of UK Biobank. Prim Care Diabetes 14:566-567. https:// doi.org/10.1016/j.pcd.2020.05.011.
31. Razieh C, Zaccardi F, Davies MJ, Khunti K, Yates T. 2020. Body mass index and the risk of COVID-19 across ethnic groups: analysis of UK Biobank. Diabetes Obes Metab 22:1953-1954. https://doi.org/10.1111/dom.14125.

32. Wang J, Xu Y, Zhang X, Wang S, Peng Z, Guo J, Jiang H, Liu J, Xie Y, Wang J, Li X, Liao J, Wan C, Yu L, Hu J, Liu B, Liu Z. 2021. Leptin correlates with monocytes activation and severe condition in COVID-19 patients. J Leukoc Biol https://doi.org/10.1002/JLB.5HI1020-704R.

33. Pietrobon AJ, Teixeira FME, Sato MN. 2020. Immunosenescence and inflammaging: risk factors of severe COVID-19 in older people. Front Immunol 11:579220. https://doi.org/10.3389/fimmu.2020.579220.

34. Niiya T, Akbar SM, Yoshida O, Miyake T, Matsuura B, Murakami H, Abe M, Hiasa Y, Onji M. 2007. Impaired dendritic cell function resulting from chronic undernutrition disrupts the antigen-specific immune response in mice. J Nutr 137:671-675. https://doi.org/10.1093/jn/137 .3.671.

35. Williams MA, Tyznik AJ, Bevan MJ. 2006. Interleukin-2 signals during priming are required for secondary expansion of CD8+ memory T cells. Nature 441:890-893. https://doi.org/10.1038/nature04790.

36. Frasca D, Diaz A, Romero M, Blomberg BB. 2020. Leptin induces immunosenescence in human B cells. Cell Immunol 348:103994. https://doi.org/ 10.1016/j.cellimm.2019.103994.

37. Wong AT, Tsang OT, Wong MY, Lim WL, Zheng BJ, Lee SS, Lai ST, Yuen KY, Choi KW, Tso EY, Chau TN, Tong WL, Chiu MC, Yu WC, PMH SARS Study Group. 2004. Coronavirus infection in an AIDS patient. AIDS 18:829-830. https://doi.org/10.1097/00002030-200403260-00021.

38. Guo W, Ming F, Dong Y, Zhang Q, Zhang X, Mo P, Feng Y, Liang K. 2020. A survey for COVID-19 among HIV/AIDS patients in two districts of Wuhan, China. SSRN https://ssrn.com/abstract=3550029. Accessed 28 April 2020.

39. Mascolo S, Romanelli A, Carleo MA, Esposito V. 2020. Could HIV infection alter the clinical course of SARS-CoV-2 infection? When less is better. J Med Virol 92:1777-1778. https://doi.org/10.1002/jmv.25881.

40. Matarese G, Procaccini C, Pucino V, Mantzoros C. 2015. Leptin, immune function, and Inflammation. In Dagogo-Jack S (ed), Leptin. Springer, Cham, Switzerland. https://doi.org/10.1007/978-3-319-09915-6_11. 